\title{
El diseño de espacios temporales en el ámbito deportivo. Arquitectura efímera para los Juegos Lima 2019 en las sedes de Lima Golf Club y Club Lawn Tennis de la Exposición*
}

\author{
The design of temporary spaces in the sports field. \\ Ephemeral architecture for the Lima 2019 Games at the Lima Golf \\ Club and Club Lawn Tennis
}

Laura Meléndez**

Diego Rosario***

Universidad Ricardo Palma

Recibido: 30 de setiembre de 2019

Aceptado: 4 de noviembre de 2019

\section{Introducción}

Para los Juegos Panamericanos y Parapanamericanos Lima 2019 fue necesario diseñar y construir una serie de obras de arquitectura, de escala grande o pequeña, permanente o provisional. La ciudad se preparó para un evento que, después de las Olimpiadas, es uno de los más importantes del mundo. Para ello se desarrolló infraestructura sismo resistente, sostenible y accesible que cumpliera los estándares internacionales requeridos para cada deporte.

Sin embargo, no es solo la arquitectura fija o la que supone un legado para la ciudad la que tuvo lugar en este evento deportivo. A su vez, cada sede fue enriquecida con equipamientos provisionales necesarios para deportistas y espectadores; incluso, algunas sedes fueron construidas bajo la pauta de la arquitectura temporal, también llamada arquitectura efímera o de superposición.

La arquitectura efímera, en el ámbito deportivo, tiene como objetivo lograr los mejores resultados en un tiempo reducido, cualidad principal en esta rama de la arquitectura. Con infraestructura temporal se logran soluciones que podrían estar a la altura de soluciones fijas o a largo plazo.

En este texto hablaremos de las dos sedes de índole privado que albergaron los deportes de golf y tenis. ${ }^{1}$ Si bien los Juegos Panamericanos se realizaron en Lima, existe una normativa internacional, así como personal especializado y con experiencia, que estuvieron a cargo de todo el proceso de organización. Los arquitectos e ingenieros que fueron parte de la elaboración de los diseños de las sedes claramente tenían en mente los estándares internacionales y, por ende, los modelos y prototipos ya vistos en anteriores eventos deportivos.

\footnotetext{
* Antecedentes del documento. Este artículo es el testimonio de los autores sobre el trabajo de infraestructura temporal realizado durante los Juegos Panamericanos y Parapanamericanos 2019 en las sedes de Lima Golf Club y Club Lawn Tennis, respectivamente.

** Laura Meléndez Arróspide. Bachiller en Arquitectura (Universidad Ricardo Palma).

*** Diego Rosario La Rosa. Bachiller en Arquitectura (Universidad Ricardo Palma).
} 


\section{El Lima Golf Club de San Isidro}

La práctica del golf en Lima se desarrolló desde inicios del siglo XX en campos ubicados en Chucuito, Callao, y en Santa Beatriz, cerca del actual Campo de Marte. A principios de la década de 1920, un grupo de británicos aficionados al juego buscó un lugar idóneo para construir un nuevo campo de golf. Para ello, adquirieron 45 hectáreas en una zona de la ciudad en proceso de urbanización. En mayo de 1924 se inauguró oficialmente el local del club, en su ubicación actual del distrito de San Isidro.

En la sede del Lima Golf Club se desarroIlaron todas las etapas de la competencia panamericana de golf, desde las eliminatorias y semifinales hasta las finales de todas las categorías. El trabajo de montaje en esta sede tuvo un tiempo apremiante, ya que el club no podía dejar de funcionar y, al ser una sede privada, el acuerdo con el ente organizador estatal fue montar y desmontar todas las instalaciones en poco más de un mes, considerando los días de entrenamiento y competencia. En resumen, la infraestructura temporal de esta sede se entregó en cuatro etapas, entre el 10 y el 26 de julio.

La primera etapa del montaje se inició en la zona de servicio ubicada próxima a la calle General Pezet, en la cual se implementaron dos pagodas (carpas fijas) y dos tabladillos destinados a las áreas de seguridad y logística; dos módulos contenedores tipo oficina y un módulo de baño químico accesible para el área de medios de comunicación, así como otros seis contenedores convencionales como depósitos.

En la segunda etapa se realizaron los trabajos de infraestructura para cableado. Esta labor consistió en proporcionar a la sede de torres estructurales, canaletas de todo tipo y bandejas pasacables para que el proveedor de energía pueda efectuar las instalaciones. Paralelamente, se realizaron los trabajos de intervención temporal en los espacios brindados por el club, como divisiones provisionales, lo que constituye propiamente la arquitectura efímera.

En la tercera etapa comenzaron los trabajos en la zona de servicio al espectador, ubicada en el ingreso principal del club, en la avenida Camino Real. Se implementaron cua- tro pagodas y cuatro tabladillos destinados a las áreas de seguridad, control de personal, servicio al espectador y enfermería, así como siete módulos de baños químicos (seis convencionales y uno accesible). En esta zona se requerían contenedores para oficinas más grandes, debido a la mayor demanda de áreas para boletería y acreditaciones. Además, se habilitaron los espacios para la zona del personal de operaciones, ubicada cerca al ingreso, exactamente en el área de caddy house (casa club que alberga a los profesionales de golf y el almacén de palos y carretas).

En la última etapa de instalación se trabajó en la zona de campo de juego. Dentro de ella, el green es el área especialmente preparada donde está situada la bandera que indica la posición exacta del hoyo, donde se debe embocar la bola.

Asimismo, para concluir con el montaje de arquitectura temporal en esta sede, se instalaron tres astas de ceremonia para la colocación de las banderas de los países ganadores. Estas se encontraron próximas al green final, el número 18 , donde se realizaron las premiaciones. Al terminar las competencias, se procedió al desmontaje de toda la infraestructura temporal y se recogieron los módulos instalados, tanto los de oficina como los de almacén y baños.

\section{El Club Lawn Tennis de la Exposición}

Fundado en 1885, el club nació por iniciativa de inmigrantes ingleses apasionados del tennis. Inicialmente estuvo localizado en parte de lo que hoy corresponde al Parque de la Exposición. A inicios del siglo XX se mudó a su actual ubicación.

El Club Lawn Tennis de la Exposición, en el distrito de Jesús María, fue el lugar donde se desarrollaron competencias panamericanas y parapanamericanas de tennis. Para ello se tuvo que adecuar todas las instalaciones del club a la accesibilidad de los deportistas. El cronograma de obras y labores en esta sede se dividió en dos partes, primero los juegos panamericanos y luego los parapanamericanos. Todo el trabajo se dio en cuatro etapas. Desde el inicio la sede fue entregada en su totalidad a la organización de los juegos, por lo que el trabajo se pudo dar de manera más 
efectiva. Se realizaron obras civiles para su adecuación, entre ellas, se tuvo que determinar, compactar y confitar un área en la zona de servicio ubicada próxima al ingreso de la avenida Salaverry.

En la primera etapa se inició el montaje de las carpas de mayor dimensión y también las más importantes para albergar las áreas funcionales imprescindibles del evento deportivo, como la sala de equipos tecnológicos y la oficina de resultados (áreas de gestión de deportes y jueces), así como trabajos de infraestructura para cableado.

En la segunda etapa se realizaron instalaciones temporales en las áreas existentes del club y, en la tercera, se terminaron de instalar las pagodas, tribunas para espectadores, plataformas para cámaras y jueces, así como módulos de baños químicos (tanto los convencionales como los accesibles). También se ejecutaron trabajos de accesibilidad y seguridad como la instalación de rampas, plataformas, luces de emergencia y señalética.

Posteriormente, en la cuarta etapa (Juegos Parapanamericanos), se realizaron trabajos de mantenimiento y reparación de los daños ocasionados durante la primera fase de los juegos. La accesibilidad tuvo que contemplarse de manera especial durante esta etapa.

Habiendo culminado las competencias, se dio inicio al desmontaje de la infraestructura temporal. La extensa área que fue compactada y rellenada con confitillo era una cancha de fútbol, que tuvo que recuperarse, optándose por colocar planchas de césped ya crecido sobre el terreno. Paralelamente se realizó el desmontaje del resto de la sede priorizando las áreas interiores del club debido a que, al igual que en Lima Golf, debían devolverse los espacios cuanto antes. En ese momento fueron retirados los módulos de almacén, oficina y baños.

\section{Notas}

1 Las empresas a cargo de la licitación de esta área fueron tres: EXPOSISTEMAS (Perú) a cargo de la arquitectura e infraestructura temporal, GL (Francia) a cargo de la dotación de energía y MTD (Brasil) a cargo del suministro de agua.

2. Mientras en el Club Lawn Tennis se daban las competencias panamericanas de tenis, en el Club el Golf eran

\section{Reflexiones finales}

En ambas sedes el equipo de trabajo fue el mismo, tanto en las áreas de la organización como de gerencia, así como las empresas a cargo de las licitaciones. Cabe resaltar, también, que las sedes de entrenamiento eran las mismas que las de la competencia, debiéndose atender a todos los tenistas y golfistas que requerían prepararse, por lo que los trabajos se dieron de manera correlativa. $^{2}$

El resultado final fue bueno. Incluso, la sede del Lawn Tennis fue considerada una de las más accesibles y la sede Lima Golf una de las que fue devuelta más rápido sin ocasionar daños; sin embargo, todos los trabajos pudieron realizarse con mayor anticipación. En la planificación de los Juegos Panamericanos se priorizó la construcción o remodelación de las principales sedes como el Complejo Deportivo Villa María del Triunfo, la VIDENA o el Polideportivo Villa El Salvador. No se tuvo en cuenta que algunas de las sedes existentes no estaban en condiciones para realizar en ellas adaptaciones temporales y que antes debían realizarse modificaciones arquitectónicas en varios sectores. Ya en el transcurso de las labores se tuvo que tomar decisiones y hacer dichas variaciones. Un último punto a recalcar es que muchas de las empresas contratistas, así como el personal que laboró durante los juegos, han sido en su mayoría extranjeros que tenían las herramientas, conocimiento y experiencia para un acontecimiento deportivo internacional, aunque en algunos casos se haya podido contratar personal peruano. Los Juegos Panamericanos y Parapanamericanos Lima 2019 fueron, finalmente, un evento internacional sin antecedentes en nuestra ciudad y un gran reto para todos los involucrados. los entrenamientos de tenis; al culminar esta primera parte de los juegos, ya estaban por iniciar los entrenamientos y las competencias panamericanas de golf. Igualmente, al culminar estos, se realizaron las adaptaciones para los juegos parapanamericanos de tenis, con lo que iniciaron las últimas competencias del evento deportivo. 


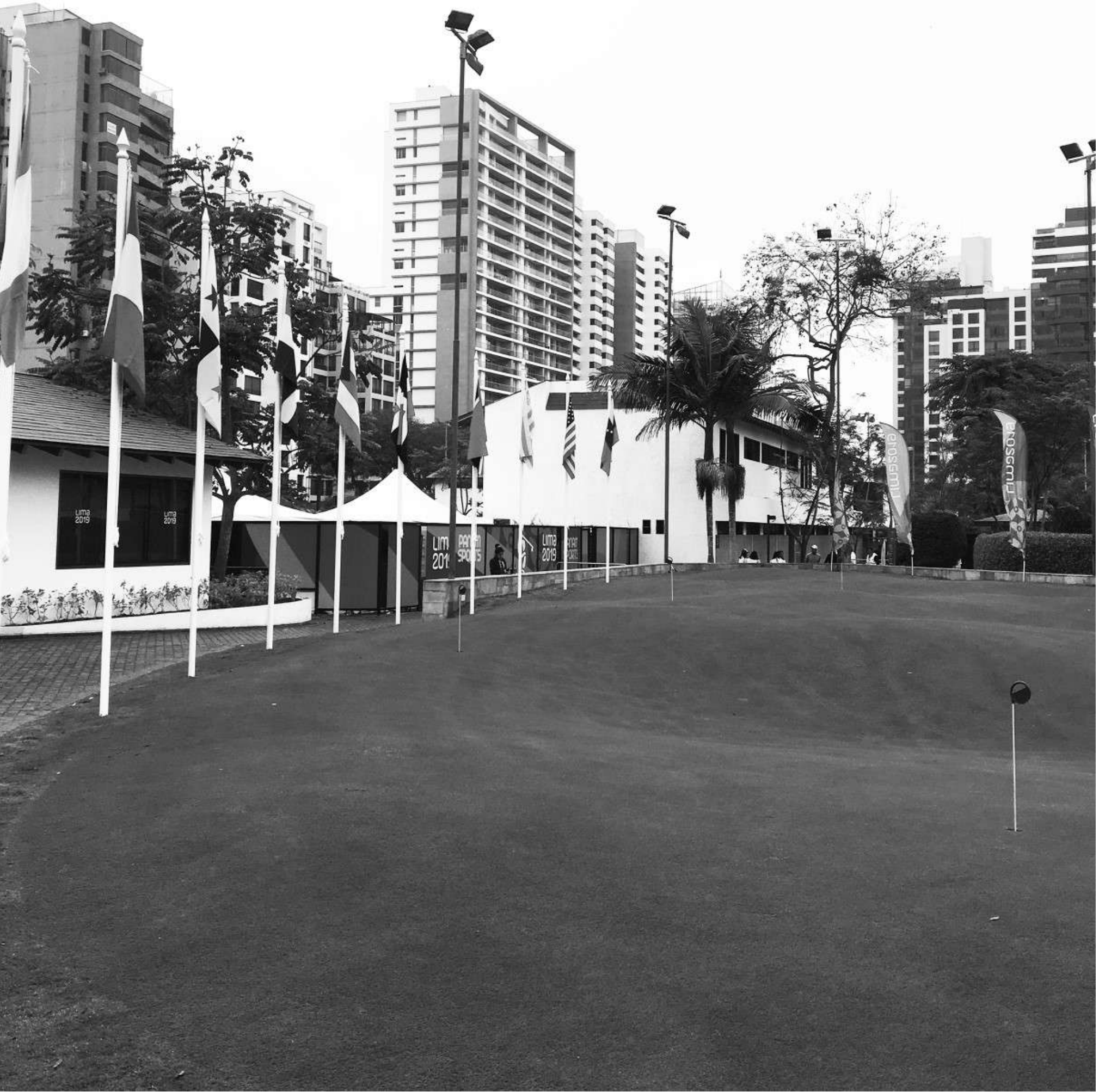




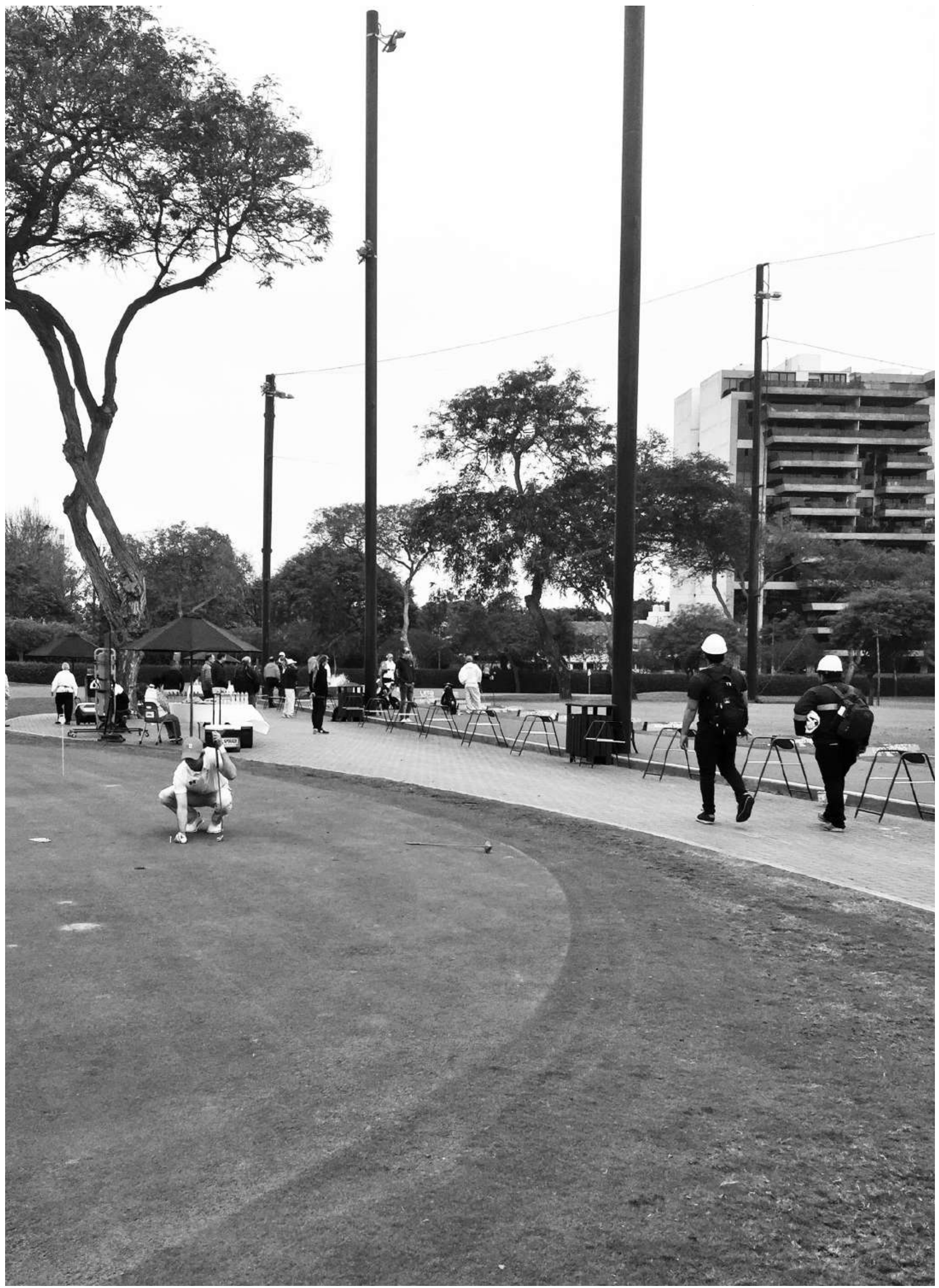




\section{ARQUITEXTOS}

ISSN 1819-2939

Año 26, No 34, enero-diciembre de 2019

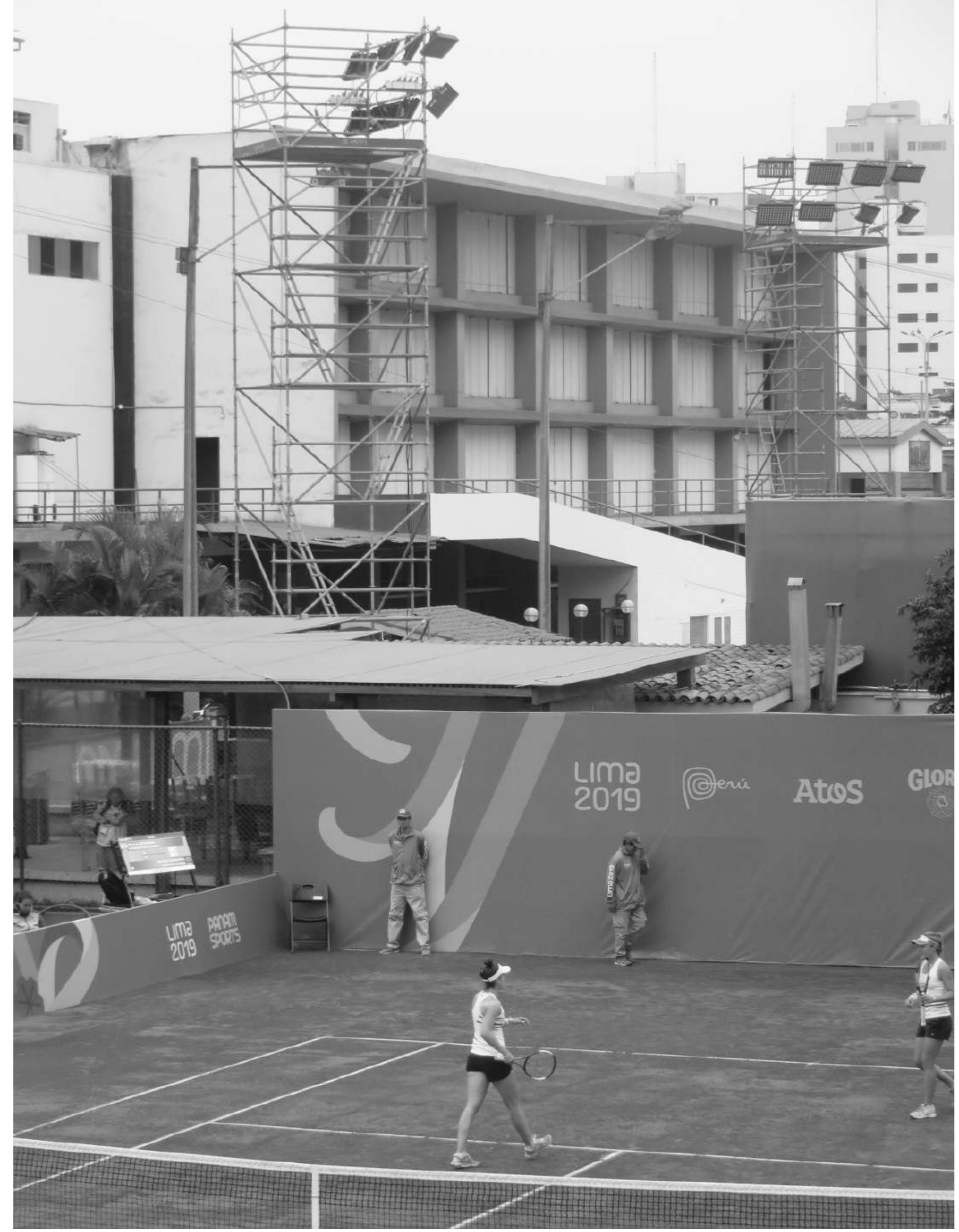

Club Lawn Tennis. JJ.PP. Lima 2019. Cancha alterna. Foto E. Martuccelli, 2019 


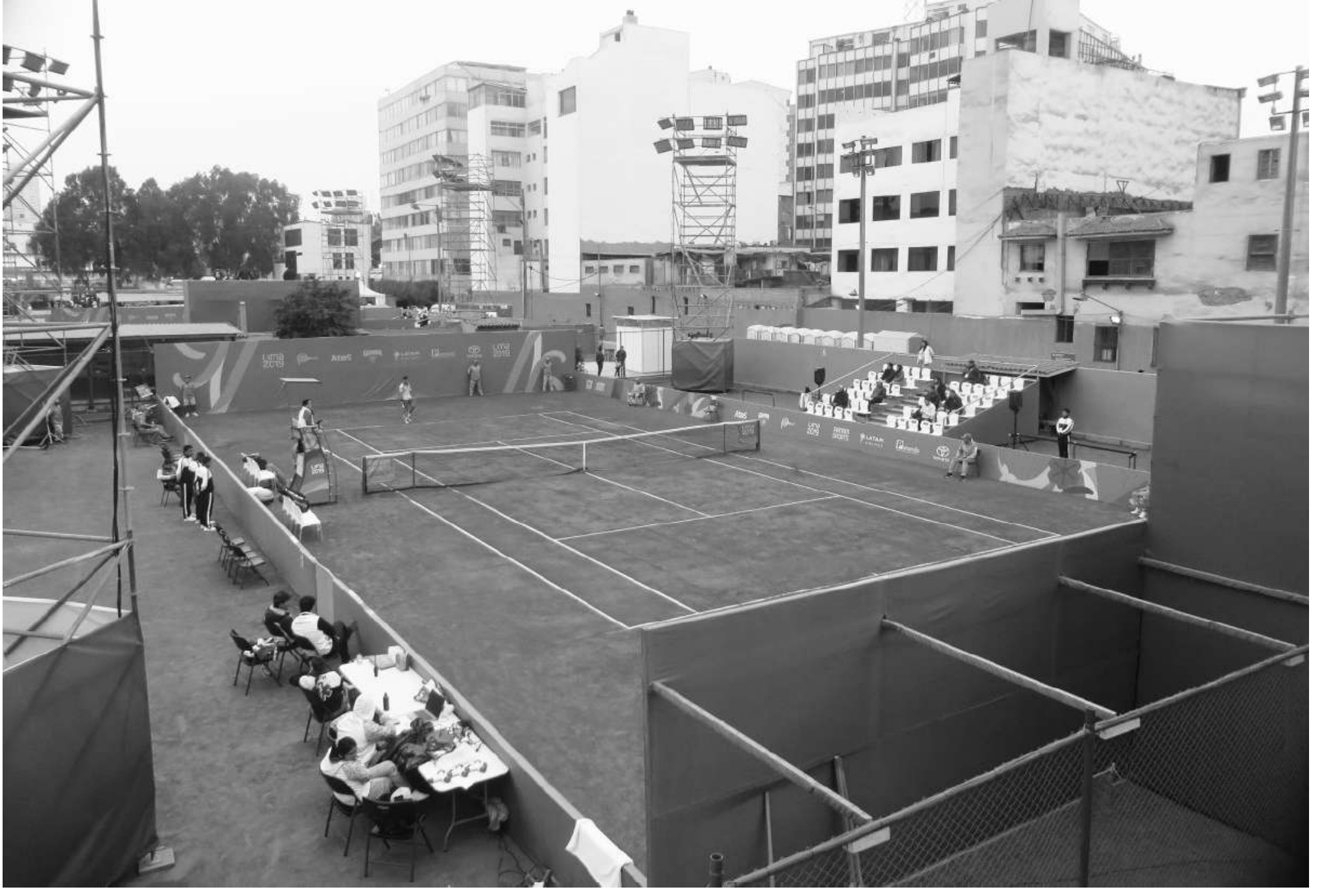

Club Lawn Tennis de la Exposición. Instalaciones temporales en la cancha alterna. Foto E. Martuccelli. 2019

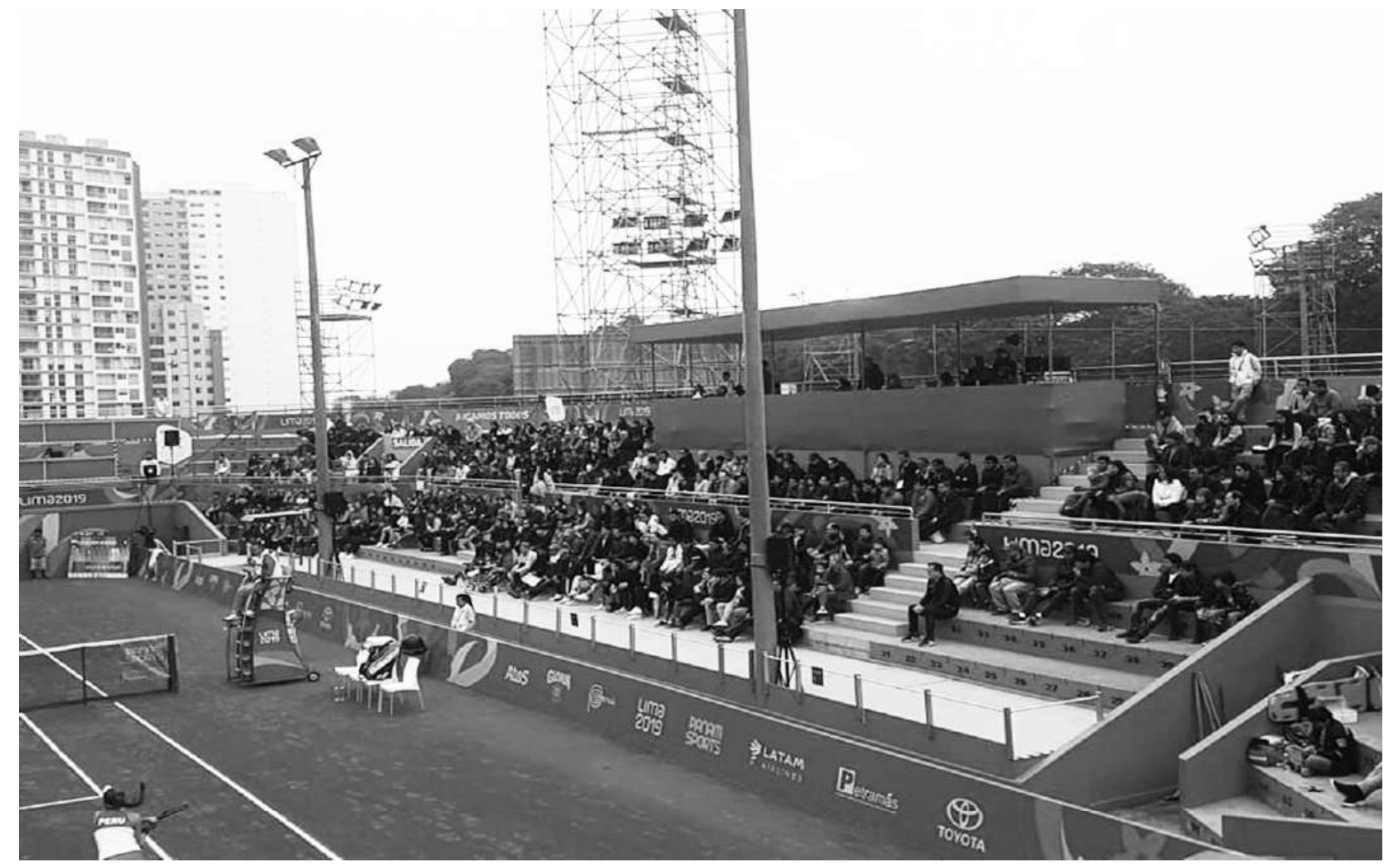

Club Lawn Tennis. Cancha central. Zona de espectadores y plataforma de cámaras. Foto L. Meléndez. 2019. 
2y

179 तथा

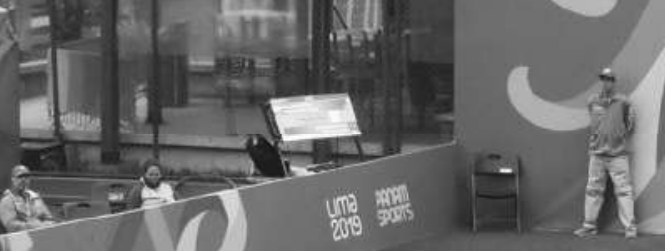

(1)

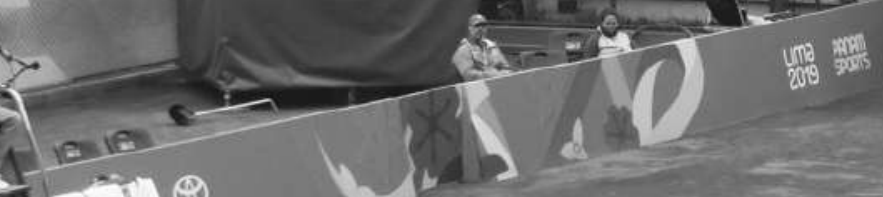

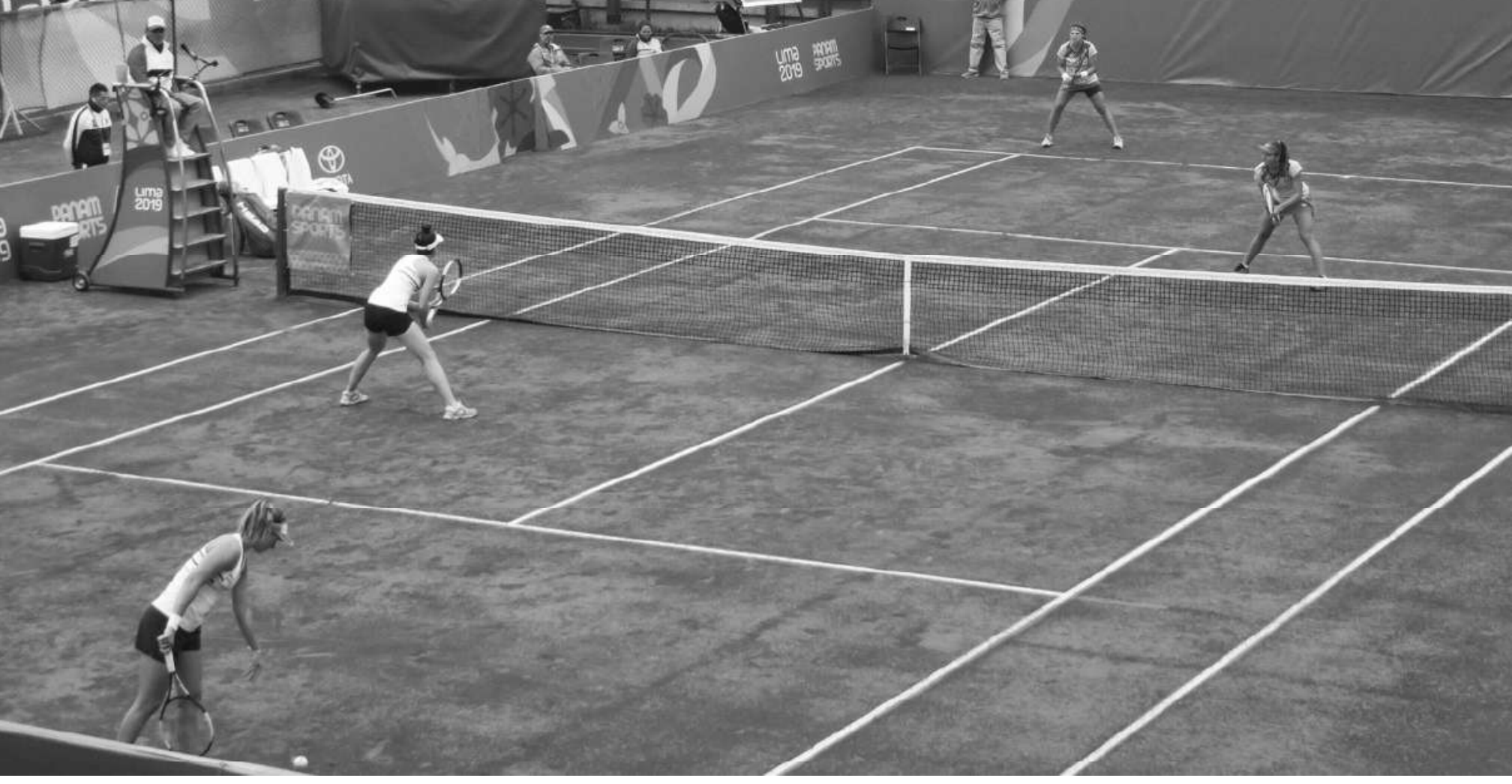

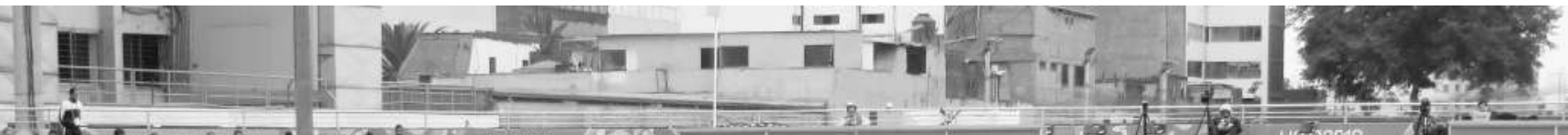
4.

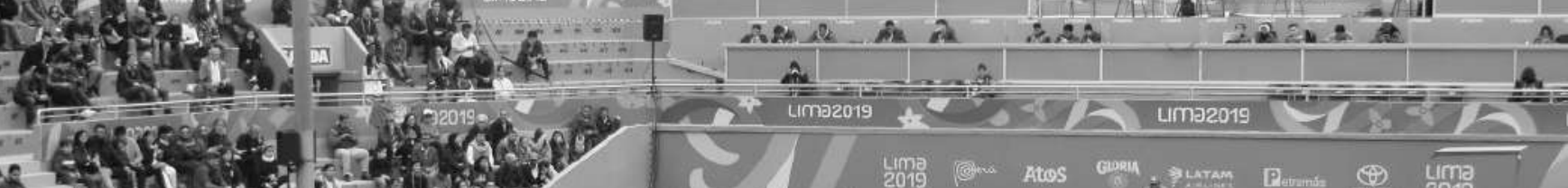

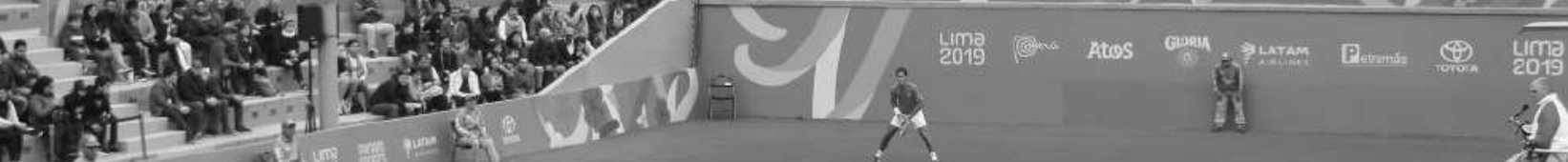

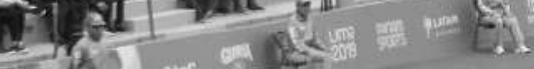
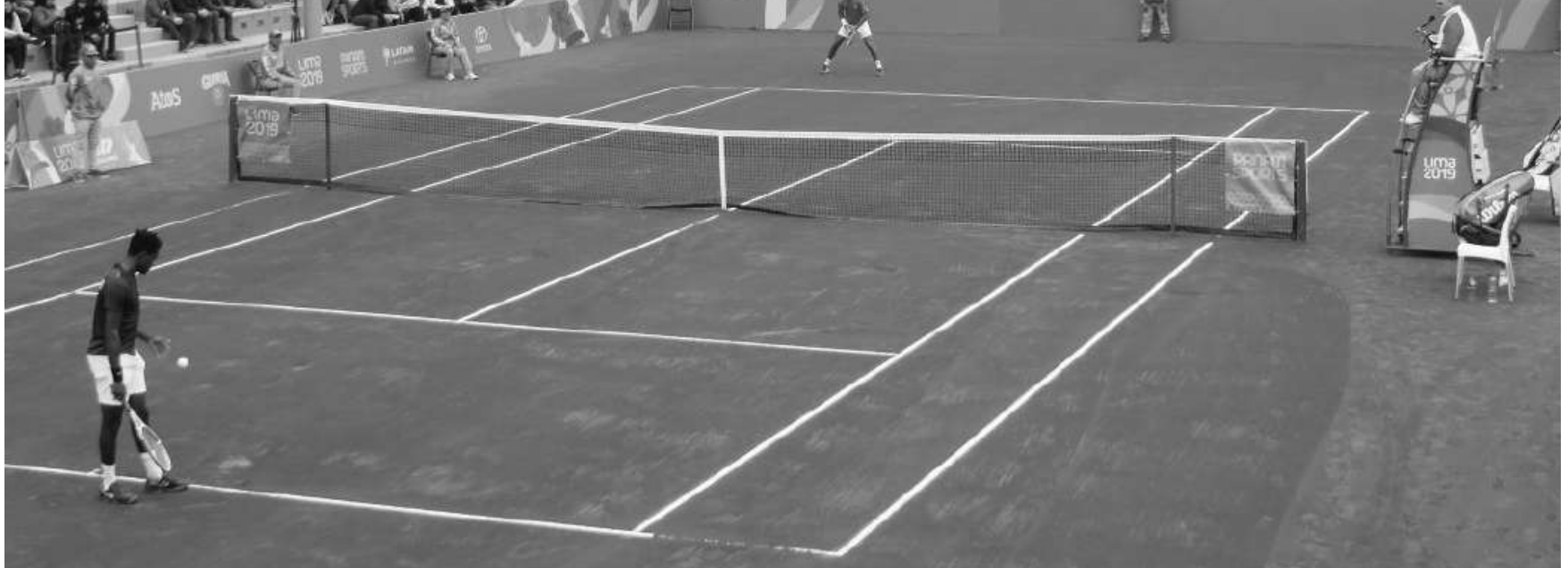


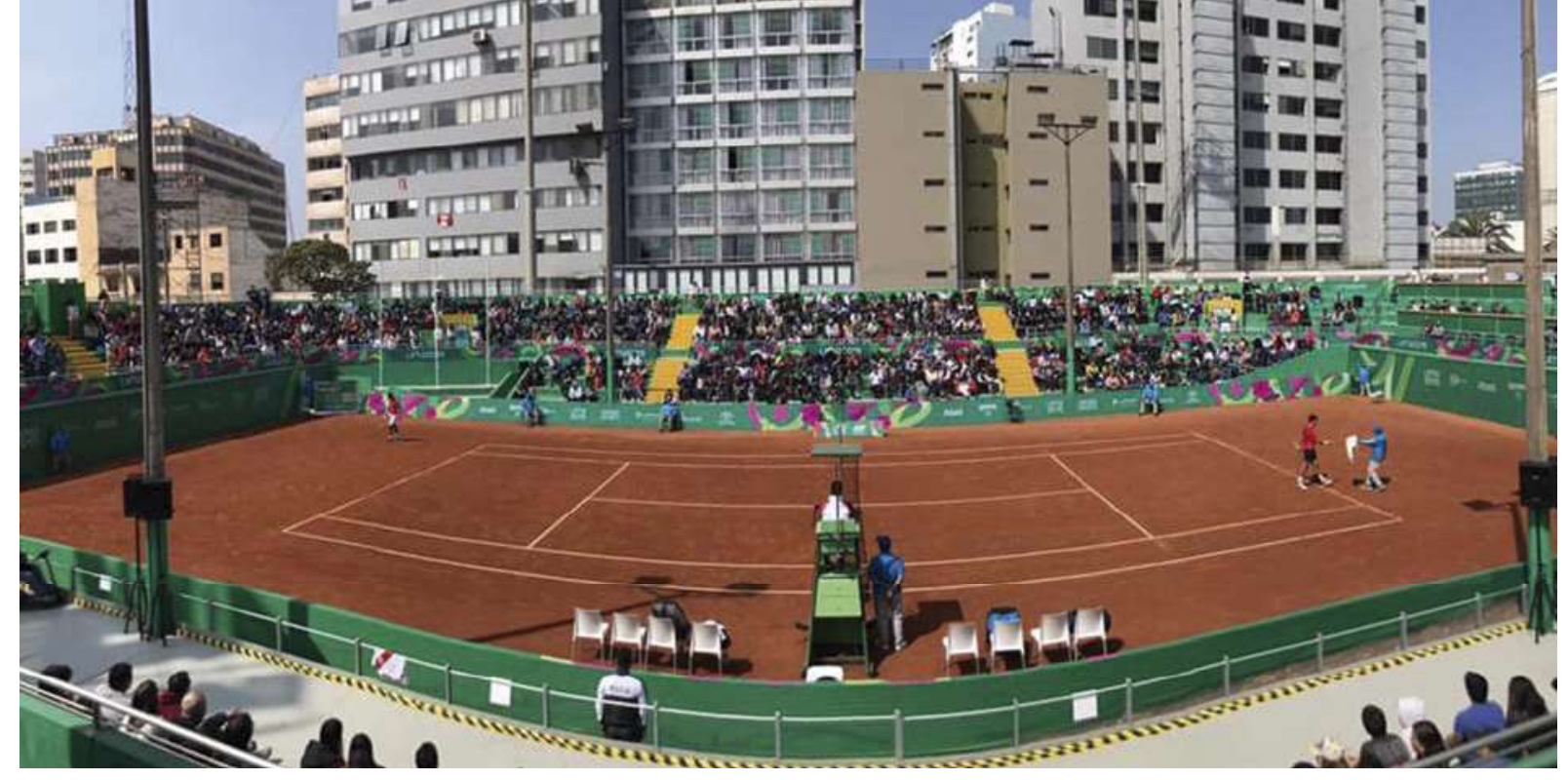

Club Lawn Tennis de la Exposición. Inicio de la competencia panamericana. Foto Diego Rosario. 2019.

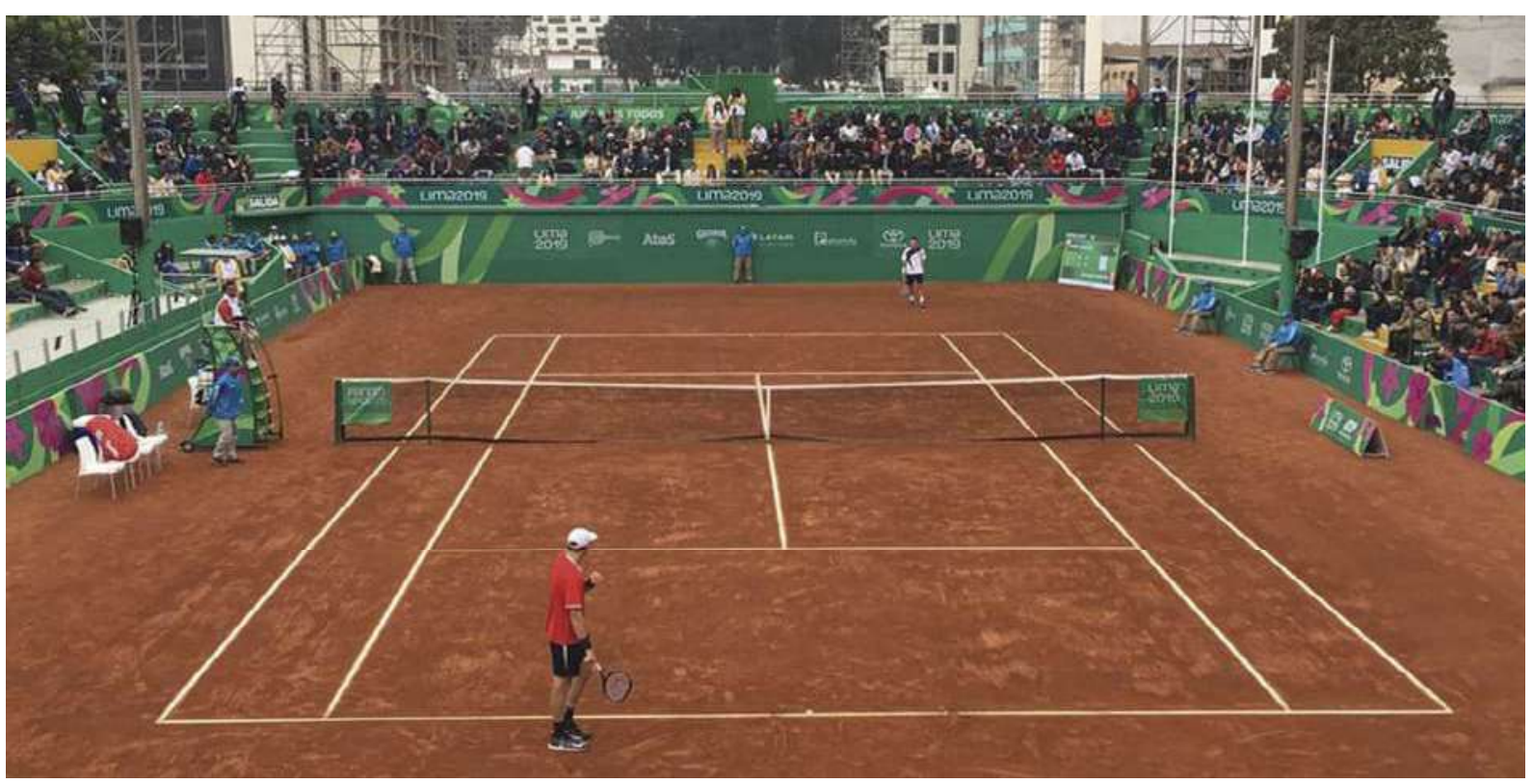

Club Lawn Tennis. Competencia panamericana en la cancha central. Foto Diego Rosario. 2019.

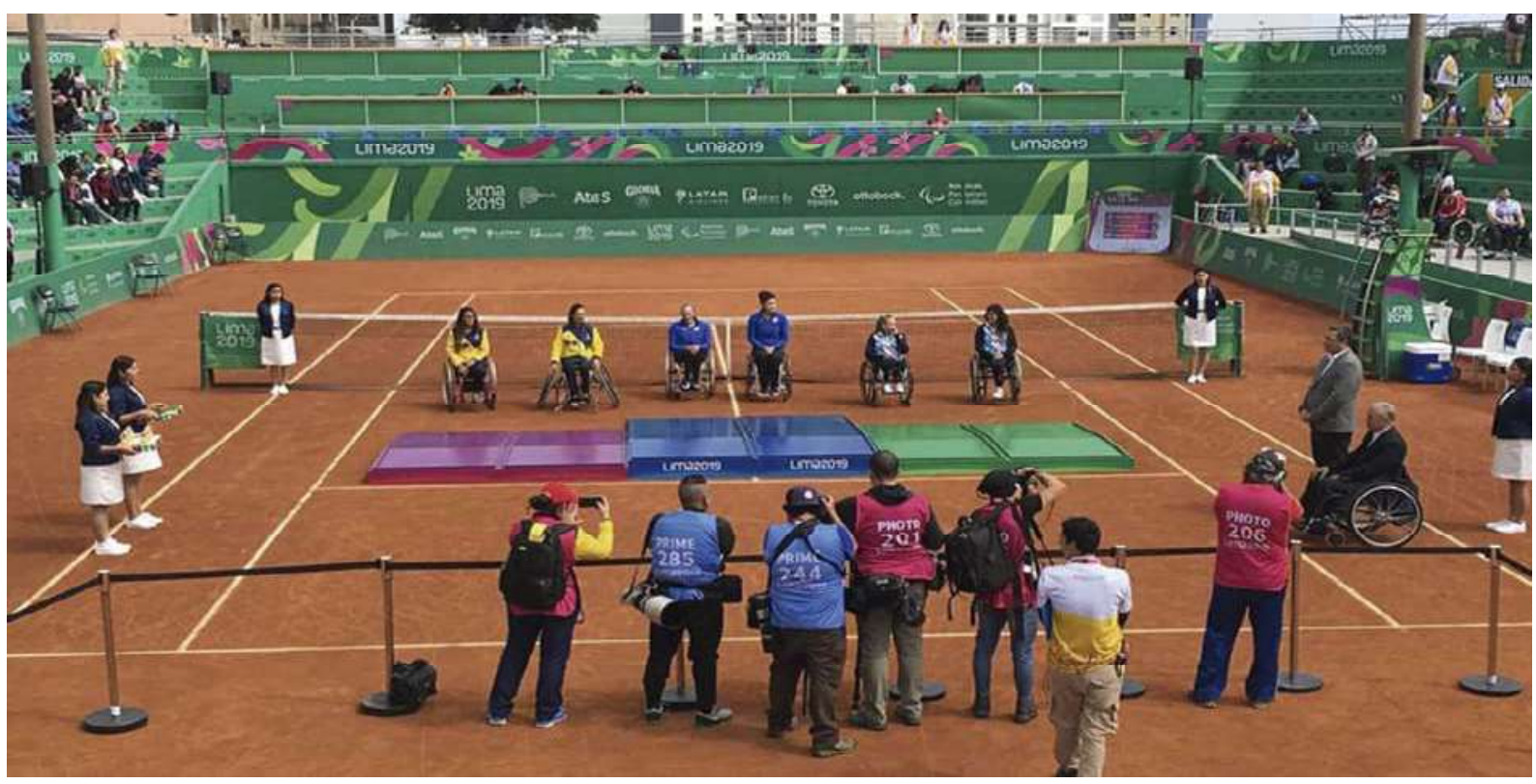

Club Lawn Tennis. Premiación panamericana en categoría dobles femenino. Foto Laura Meléndez. 2019. 
